ISSN: 2224-0616

Int. J . Agril. Res. Innov. \& Tech. 2 (2): 44-47, December, 2012 Available online at http://www.ijarit.webs.com

\title{
RESPONSE OF DIFFERENT COMBINATIONS OF MANURE AND FERTILIZERS TO THE YIELD OF RAPE CROP
}

\author{
S.P. Baliyan"*, P.S. Baliyan ${ }^{2}$ and K.S. Madhava Rao ${ }^{3}$ \\ Received 19 October 2012, Revised 18 December 2012, Accepted 25 December 2012, Published online 31 December 2012
}

\begin{abstract}
This study was an attempt to determine the effect of different combinations of manure and fertilizers on the yield of rape crop so as to improve yield by recommending the best combination of manure and fertilizers to the rape growers in Botswana. Rape crop was planted on farmers field in a complete randomized block design where nine different combinations of manure and fertilizers, namely, chicken manure (Ch); Ch and NPK (2:3:2); Ch and Fe (Iron); Ch, NPK and Fe; Ch and Urea; Ch, NPK and Urea; Ch, Urea and Fe; Ch, NPK, Urea and Fe; and control (No application of manure and fertilizer) were considered. Each fertilizer combination was replicated four times in a total of thirty six plots in the layout of the experiment. The data on rape yield was collected. The leaves of rape were harvested three times a month and the rape yield (in $\mathrm{kg}$ ) was recorded in a harvest sheet. A two way analysis of variance (ANOVA) was performed using the SPSS software. The results indicated that fertilizer combination of chicken manure, NPK and Urea produced the highest yield of rape which was 2.61 times higher than the yield produced by the control plots (where no manure and fertilizer was applied) and therefore, a fertilizer combination of chicken manure, NPK and Urea was recommended to the rape growers. Suggested future studies included the comparative profitability of different fertilizer combinations as well as the effects of different doses of the organic and inorganic fertilizers on rape production.
\end{abstract}

Keywords: Fertilizers Response, Fertilizer Combinations, Organic and Inorganic Fertilizers, Rape Production Improvement, Soil Fertility

${ }^{1}$ Department of Agriculture, Livingstone Kolobeng College, Gaborone, Botswana

${ }^{2}$ Department of Accounting and Finance, University of Botswana, Gaborone, Botswana

${ }^{3}$ Department of Statistics, University of Botswana, Gaborone, Botswana

*Corresponding author’s email: spbaliyan@ yahoo.com (S.P. Baliyan)

\section{Introduction}

Vegetables are important protective food and highly beneficial for the maintenance of health and prevention of diseases including malnutrition deficiencies as they contain high quality of minerals, vitamins and fiber. Rape (Brassica napus) is a major leafy vegetable crop grown during the times of the year when the temperature is low (Acquaah, 2005; Decoteau, 2000). Rape production among small holder farmers is important for its nutritional and income generation (FAO, 1997; Acquaah, 2005). The rape is grown by most of the small scale farmers in Botswana but they are not harvesting enough and good quality yield and therefore, the farmers have not been able to to meet out the local demand which force to import vegetables from South Africa. There are various constraints resulting in low production of vegetables including rape in Botswana which include poor soil fertility, water scarcity, poor cultivation skills, pest and disease attack, poor availability of inputs and harsh climate (Baliyan and Kgahti, 2009). The soils in
Botswana have been broadly characterized into poor sandy soils which are lacking in nutrients and require improvement by the addition of organic matter and chemical fertilizers for successful production of vegetable crops like rape (Belien, 1997 and Braun, 1975). Growing of vegetables requires knowledge and skills of both crop production and business practices (Williams, 1984). In order to harvest high yields of quality produce, there is a need to plan each production step and follow all cultural practice including application of proper fertilizers.

The small scale farmers in Botswana are not aware of the use and the effect of different manure and fertilizers on the rape production and therefore are not practicing any manure and fertilizer application strategies (Staring, 1979; Staring, 1979). Rape requires thirteen essential nutrients elements for its proper growth as it is the case for most other green leafy vegetables. All these elements are equally essential and cannot be replaced by other nutrients. With a complete lack or insufficient supply of nutrients, normal 
rape growth cannot take place (Mengel and Kirkby, 2001). Soils in Botswana are poor which leads to poor growth and yield of the rape. Different types of fertilizers (organic and inorganic) are available to improve the soil fertility. Organic fertilizers such as compost, chicken manure and kraal manure are commonly used in growing of vegetables including rape. Since rape crop has a high nutritional requirement, organic fertilizers cannot constantly supply all the nutrients to its requirement and therefore, inorganic fertilizers have to be used to ensure proper growth and yield of rape crop. Organic and inorganic fertilizers can be combined and applied to boost the constant supply of the essential nutrients but their response on the yield of rape is not well known. Therefore, this experiment was conducted to find out the most effective combination of manure and fertilizer for rape crop so as to convenience rape growers on the effect of application of different fertilizers.

The objective of this study was to determine the effect of different combinations of manure and fertilizers on the yield of rape crop and therefore to recommend the best combination of manure and fertilizers to the rape growers in Botswana. In order to fulfill the objectives of the study, the null and the alternative research hypotheses of interest were stated as follows:

$H_{0}$ :The nine combinations of fertilizers have equal effects on the total yield of rape
$H_{1}$ : The nine combinations of fertilizers do differ in their effects on the total yield of rape

$H_{0}^{*}$ :The four blocks have equal effect on the total yield of rape

$H_{1}^{*}$ :The four blocks do differ in their effects on the total yield of rape

\section{Materials and Methods}

The seeds of a recommended variety of rape for Botswana (English Giant) were planted in a seed bed during the winter season and then four weeks old seedlings were transplanted in the prepared thirty six experimental plots. The plot size was $6 \times 2.4$ meter with a spacing of $60 \times 40$ $\mathrm{cm}$ (Row to row $\times$ Plant to plant) and thus 4 rows of 6 meter length were planted in each plot. A Complete Randomized Block Design was adopted for the experiment and the treatments were allocated through randomization using a random sampling method in each of the four blocks. Nine different combinations of manure and fertilizers namely chicken manure $(\mathrm{Ch}), \mathrm{Ch}$ and NPK (2:3:2); Ch and Fe (Iron); Ch, NPK and Fe; Ch and Urea; Ch, NPK and Urea; Ch, Urea and Fe; Ch, NPK, Urea and Fe; and control (No application of manure and fertilizer) were considered as treatments for the experiment (Table 1). Thus each treatment was replicated four times among the four blocks giving a total of thirty six plots in the layout of the experiment.

Table 1. Different fertilizer combinations (treatments) used in the experiment

\begin{tabular}{ll}
\hline Treatments & Combination of fertilizers \\
\hline Treatment 1 & Chicken manure (Ch) \\
Treatment 2 & Chicken manure, NPK (2:3:2) \\
Treatment 3 & Chicken manure, Fe (Iron) \\
Treatment 4 & Chicken manure, NPK, Fe \\
Treatment 5 & Chicken manure, Urea \\
Treatment 6 & Chicken manure, NPK, Urea \\
Treatment 7 & Chicken manure, Urea, Fe \\
Treatment 8 & Chicken manure, NPK, Urea, Fe \\
Treatment 9 & Control (No application of any manure and fertilizer) \\
\hline
\end{tabular}

All the manure and fertilizers were applied at the suggested rates using recommended methods of their application (Table 2). All the recommended management and cultural practices such as watering, weeding and pest and disease control were strictly followed throughout the experimentation period.

Table 2. Rates and application methods of manure and fertilizers used in the experiment

\begin{tabular}{lccc}
\hline Manure/ Fertilizer & Quantity applied $\left(\mathrm{Kg} \mathrm{ha}^{-1}\right)$ & Application method & No. of Application \\
\hline Chicken manure & 20000 & Basal & One \\
NPK & 1000 & Basal & One \\
Urea & 100 & Top dressing & every 3 weeks \\
Iron (iron chelates) & $500 \mathrm{mg}$ & Foliar spray & 4 sprays \\
\hline
\end{tabular}

The data on rape yield was collected. The rape crop was harvested three times a month giving a total of nine harvests. Only the two central rows of rape in each plot were harvested as a precautionary measure to avoid the leaching effect of the nutrients from the neighboring plots 
which may have affected the yield of rape and therefore the results of the study. The yield obtained from each plot for each harvest was weighed and recorded in a pre-structured harvest sheet. The total yield of rape for different treatments was calculated by adding the yield obtained from all the harvests of rape crop from all the respective treatments plots. Data were entered in SPSS software and a Two Way Analysis of Variance (ANOVA) was performed to determine the significance of difference between the means of rape yield from different combinations of fertilizers (treatments) and effect of blocking the experimental field. The treatment means were separated by the Least Significant Difference (LSD Turkey test) at alpha $\leq$ 0.05.

\section{Results and Discussion}

The output of Two Way Analysis of Variance (ANOVA) is presented in Table 1. The two way

Table 3. Influence of different combinations of fertilizers on the yield of rape

\begin{tabular}{lccccc}
\hline Source & SS & df & MS & F & Sig \\
\hline Blocks & 89.450 & 3 & 29.817 & 2.102 & 0.126 \\
Treatments & 1036.292 & 8 & 129.537 & 9.133 & 0.0001 \\
Error & 340.388 & 24 & 14.183 & & \\
Total & 1466.130 & 35 & 14.13 & \\
\hline
\end{tabular}

The multiple comparisons based on LSD principle reveal that the following seventeen combinations

of treatments out of the $\left(\begin{array}{l}9 \\ 2\end{array}\right)=36$ combinations

are significant at $5 \%$ level.

(Ch, Ch NPK), (Ch, Ch Urea), (Ch, Ch NPK Urea), (Ch, Ch Urea $\mathrm{Fe}$ ), (Ch, Ch NPK Urea Fe), (Ch NPK, Ch NPK Urea), (Ch NPK, Control), (Ch Fe, Ch NPK Urea), (Ch Fe, Control), (Ch NPK Fe, Ch analysis of variance reveals that the treatments differ significantly $(p-$ value $<0.0001)$, while there are no significant block effects $(p-$ value $=0.126)$. In other words, the nine fertilizer combinations (treatments) namely, Ch; Ch NPK; Ch Fe, Ch NPK Fe; Ch Urea; Ch, NPK Urea; Ch, Urea, Fe; Ch, NPK, Urea, Fe; and Control contribute differently to the total yield of rape. However, the total yield does not seem to be impacted by how the experimental fields were laid out in terms of blocks in the study design which indicates that the differences in the rape yield was only because of the effects of the different combinations of fertilizers considered in the experiment.

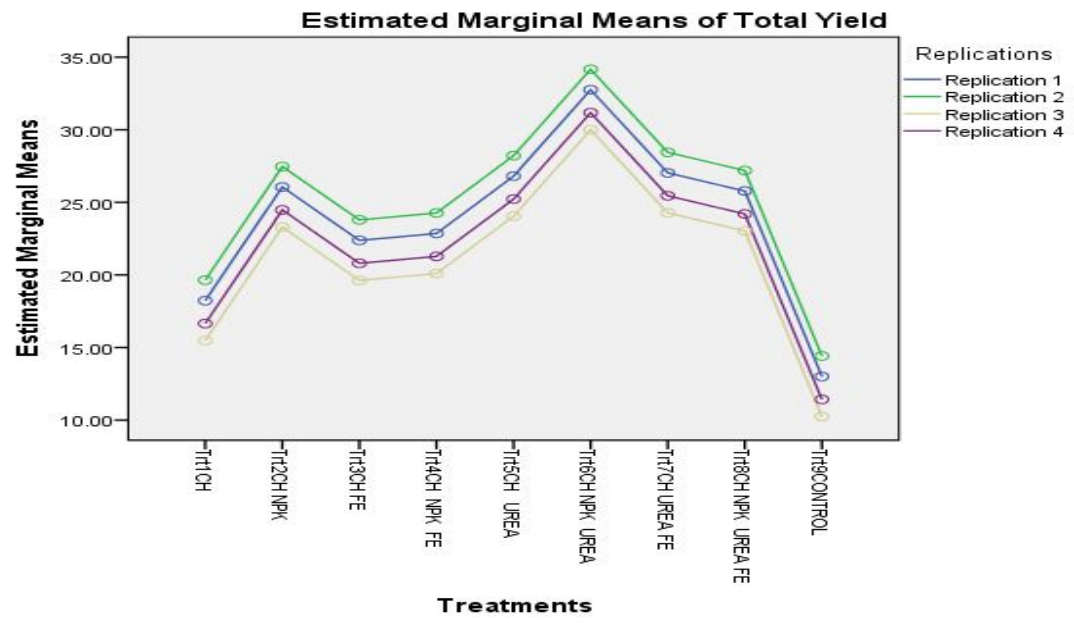

Fig. 1. Estimated marginal means of total yield of rape over the four replications (blocks) 
It is observed from Figure 1 that the fertilizer combination (Ch NPK Urea) emerges as the best fertilizer combination to be replicated in the blocks to maximize the rape yield as this fertilizer combination has produced the highest yield of rape $(128.1 \mathrm{~kg})$ followed by $\mathrm{Ch}$ Urea $\mathrm{Fe}$ and $\mathrm{Ch}$ Urea which produced total rape of $105.2 \mathrm{~kg}$ and $104.3 \mathrm{~kg}$, respectively. The treatment Ch produced the lowest total yield $(70 \mathrm{~kg})$ among the eight combinations of fertilizer treatments. As expected the Control (no application of fertilizers) resulted in the lowest total yield of $49.1 \mathrm{~kg}$ of rape because no nutrients were supplied to the rape crop. These results reflected that NPK is an important source of nutrients for improving the yield of rape because Ch Urea Fe and Ch Urea have produced almost the same yield of rape where as the Ch NPK Urea fertilizer combination has not only produced the highest yield $(128.1 \mathrm{~kg})$ but also the yield difference between Ch NPK Urea and the two fertilizer combinations of (Ch Urea Fe and Ch Urea) varied from $22.9 \mathrm{~kg}$ to $23.8 \mathrm{~kg}$. Therefore, it was concluded the application of NPK fertilizer is responsible for this difference in rape yield. However, it should also be noted that NPK is one of the expensive fertilizers for farmers in Botswana and therefore profitability analysis of rape production with and without NPK fertilizer should be conducted so as to maximize the income from rape production.

\section{Conclusion and Recommendations}

Results of this study indicated that the application of the manure and fertilizers can not only increase the yield of rape but excess application of nutrients (especially nitrogen) also reduces the yield of rape. The results have indicated that chicken manure, NPK and urea emerged the best fertilizer combination because it produced the highest yield of rape. Therefore, the rape growers were recommended to use the best combination of manure and fertilizers to obtain the higher yield of rape crop. This study provides directions for conducting experiments in future in the areas of:

- Response of different combinations of manure and fertilizers to the yield of rape crop on different types of soils. To find out the best treatment for getting the highest yield of rape in different types of soils.

- Response of different doses of the treatments used in this experiment to the yield of rape crop: To find out the best dose of the treatments for getting the highest yield of rape.

- Response of different doses of the treatments used in this experiment to the quality of rape crop: To find out the best dose of the treatments for getting the best quality yield of rape.
- Comparative economic profitability of fertilizer combinations of Ch NPK Urea, in rape production: To find out the best profitable combination of the fertilizers for obtaining the highest income and profit in rape production.

\section{Acknowledgement}

The corresponding author would like to acknowledge the support from the Department of Agricultural Research, Ministry of Agriculture, and Republic of Botswana for providing the opportunity to conduct this experiment during his tenure as an Agricultural Research Officer. He would also like to thank Dr. G.C. Wiles for the immense technical support during the conduction of this research.

\section{References}

Acquaah. 2005. Horticulture: Principles and Practices ( $3^{\text {rd }}$ Ed.) Pearson Education, Inc: New Jersey. 817p.

Baliyan, S.P. and Kgathi, D.L. 2009. Production and marketing problems in small scale horticultural farming in Botswana. Proceeding of the XVI International Symposium on Horticultural Economics and Management. Acta Hort. (ISHS). 831: 31-40.

Belien, J.S. 1977. Research Agronomist's Interim Report, Technical Document No. 7, UNDP FAO Project BOT/72/019: Swamp and Dryland Soils of the Okavango.155 p. Braun, B.H. 1975. Investigations on the soils at Motopi and Moshu, Technical Note No. 3, UNDP FAO Project BOT/ 72/ 019. 144 p.

Decoteau, D.R. 2000. Vegetable crops. PrenticeHall, Inc, New J ersey. 464 p.

FAO. 1997. Agriculture, food and nutrition for Africa: A resource book for teachers of agriculture. FAO Publishing managerial group, Rome, Italy. 308 p.

Mengel, K. and Kirkby, E.A. 2001. Principles of plant nutrition (5 $5^{\text {th }}$ Ed.) Kluwer Academic Publishers, Dordrecht. 849 p.

Staring, G. 1979. Results of agronomic trials during 1978/79, Field document no. 16, UNDP FAO Project BOT/72/019: Swamp and Dryland Soils of the Okavango. $16 \mathrm{p}$.

Staring, G. 1980. Soil, Water and Crop Production in Ngamiland, Field Document No. 15, UNDP FAO Project BOT/72/019: Swamp and Dry land Soils of the Okavango. $33 \mathrm{p}$.

Williams, R.D. 1984. Institute of Food and Agricultural Sciences, University of Florida. Gainesville, 32611. 105 p. 